\title{
Antisaccades in Parkinson's Disease: A Meta-Analysis
}

\author{
Josefine Waldthaler ${ }^{1,2}$ (1) $\cdot$ Lena Stock $^{1} \cdot$ Justus Student ${ }^{1} \cdot$ Johanna Sommerkorn ${ }^{1} \cdot$ Stefan Dowiasch $^{2,3,4}$. \\ Lars Timmermann ${ }^{1,2}$
}

Received: 16 August 2020 / Accepted: 18 February 2021 / Published online: 19 March 2021

(c) The Author(s) 2021

\begin{abstract}
The usefulness of eye-tracking tasks as potential biomarkers for motor or cognitive disease burden in Parkinson's disease (PD) has been subject of debate for many years. Several studies suggest that the performance in the antisaccade task may be altered in patients with PD and associated with motor disease severity or executive dysfunction. In this meta-analysis, random effects models were used to synthesize the existing evidence on antisaccade error rates and latency in PD. Furthermore, meta-regressions were performed to assess the role of motor and cognitive disease severity, dopaminergic medication and methodological factors. Additionally, the impact of acute levodopa administration and activation of deep brain stimulation was evaluated in two separate sub-analyses.

This meta-analysis confirms that antisaccade latency and error rate are significantly increased in PD. Disease duration, Unified Parkinson's disease rating scale score and Hoehn and Yahr stage mediate the effect of PD on antisaccade latency with higher motor burden being associated with increased antisaccade latency.

Acute administration of levodopa had no significant effects on antisaccade performance in a small number of eligible studies. Deep brain stimulation in the subthalamic nucleus, on the other hand, may alter the speed accuracy trade-off supporting an increase of impulsivity following deep brain stimulation in PD.

According to the results of the meta-analysis, antisaccade latency may provide a potential marker for disease severity and progression in PD which needs further confirmation in longitudinal studies.
\end{abstract}

Keywords Parkinson's disease $\cdot$ Antisaccade $\cdot$ Saccade $\cdot$ Eye movement $\cdot$ Eye-tracking $\cdot$ Executive functions

\section{Introduction}

While James Parkinson stated in his original description of Parkinson's disease (PD) that cognition was preserved in $\mathrm{PD}$, cognitive impairment, in particular a dysexecutive syndrome, is nowadays regarded as a central symptom that PD patients may present even in the earliest stages of the disease. (Kudlicka et al., 2011) As part of the executive functions, inhibition control describes the ability to suppress

Josefine Waldthaler

josefine.waldthaler@staff.uni-marburg.de

1 Department of Neurology, University Hospital Marburg, 35033 Marburg, Germany

2 CMBB - Center for Mind, Brain and Behavior, Universities Gießen and Marburg, Marburg, Germany

3 Department of Neurophysics, University of Marburg, Marburg, Germany

4 Thomas RECORDING GmbH, Giessen, Germany habitual or prepotent reflexive responses to stimuli. (Obeso et al., 2011). Impaired response inhibition may result in an increased impulsivity, i.e. a tendency to act without delay, reflection or voluntary directing (Bari \& Robbins, 2013). One of the successfully validated experimental paradigms used to explore inhibition of prepotent reflexive responses is the antisaccade task. (Everling \& Fischer, 1998) In this task, participants are instructed to look at the opposite direction of the presented target stimulus. To successfully perform an antisaccade, a faster reflexive, visually-guided saccade in the direction of the stimulus has to be suppressed and consecutively a voluntary saccade to the opposite direction has to be planned and executed. The error rate in the antisaccade task has been associated with executive functions in healthy individuals as well as several in neurodegenerative disorders. (Mirsky et al., 2011; Rodríguez-Labrada et al., 2014; Walton et al. 2015) Please see also (Leigh et al., 2015) for a comprehensive review on the neural basis of saccade control. 
Eye-tracking studies are especially suitable to assess cognitive functions in movement disorders like PD, as they do not rely on a motor response (e.g. pressing a button or pulling a lever) and, thus may be less influenced by bradykinesia in PD. However, the results of studies assessing antisaccade performance in PD patients are inconsistent, sometimes even contradictory. While no meta-analysis on the effect of PD on antisaccades has been published so far, alterations of visuallyguided saccades in PD have been reviewed in a meta-analysis in 2010 (Chambers \& Prescott, 2010): Chambers and colleagues concluded that, overall, the latencies of visuallyguided saccades are prolonged in PD. However, the latency may differ as a function of target amplitude, with small amplitudes resulting in "hyper-reflexive" saccades with decreased latencies and larger amplitudes resulting in prolonged latencies compared to healthy subjects. Hence, the high variability in task-related variables might also contribute to the inconsistent findings in antisaccade studies in PD.

While some studies demonstrated increased antisaccade error rates even in unmedicated patients in very early disease stages (Antoniades et al., 2015a; Hanuška et al. 2019), others found no significant alterations of antisaccade latency or antisaccade error rate early and later in the disease course. (Ranchet et al., 2017; Nagai et al., 2019) As proposed by two recent studies (Lu et al., 2019; Waldthaler et al., 2019a), antisaccade latency might correlate with disease duration in PD without significant impact of dopaminergic medication.

Surprisingly few studies, most with relatively small sample sizes, assessed treatment effects on antisaccades in PD so far. Dopaminergic replacement therapies as well as deep brain stimulation in the subthalamic nucleus (STN-DBS) and the internal segment of globus pallidus (GPi-DBS) might influence antisaccade performance differently and via distinct mechanisms. It has been proposed that levodopa intake may increase the latency of reflexive saccades, while it might decrease the latency of voluntarily executed saccades, like antisaccades. (Terao et al., 2013) Recently, Lu et al. supported this finding in their meta-analysis on the effect of levodopa on saccades. However, they did not replicate the decreasing effect of levodopa on antisaccade latency in their own study. (Lu et al., 2019) While antisaccade error rates might decrease after levodopa intake (Hood et al., 2007), STN-DBS studies provided inconsistent results regarding changes in antisaccade error rates. (Antoniades et al., 2015b; Goelz et al., 2017)

To shed light upon the high variability of antisaccade performance in PD, we conducted a comprehensive meta-analysis. The two most frequently reported variables were selected as principal outcome measures for antisaccade performance: the error rate and the latency. The aims of this meta-analysis were (1) to identify the extent of antisaccade deficits in PD patients compared to healthy individuals, (2) to determine the effect of levodopa medication and STN-DBS on antisaccade performance in PD and (3) to investigate clinical factors and task related variables that moderate antisaccade performance in PD.

\section{Methods}

\section{Search Strategy}

The meta-analysis was conducted in accordance with the recommendations of the Meta-Analysis of Observational Studies in Epidemiology Group, the Preferred Reporting Items for Systematic Reviews and Meta-Analyses (PRISMA) 2009 guidelines (Stewart et al., 2015) and the review protocol was submitted to PROSPERO (registration number: CRD42020204579). The systematic literature review was performed in April 2020. The search terms "("Parkinson" OR "Parkinson's") AND ("antisaccade" OR "antisaccade")" yielded a total of 129 results on PsycINFO ( $n=52)$ and PubMed $(n=77)$. After removal of duplicates, titles and abstracts of the remaining 80 records were screened by two authors separately (LS, JS or JSt and JW) to exclude editorials, comments, books and review papers as well as studies that did not report results from patients with PD. All full texts that were not excluded based on those criteria were screened for fulfillment of the following pre-defined inclusion criteria: Full length original research articles in English published until March $31^{\text {st }}, 2020$ which reported results of either a human PD group and a healthy control group or a PD group in two treatment states (on and off medication or on and off DBS) that performed an antisaccade task using any eye-tracking device. No restrictions regarding disease stage, cognitive impairment, age, or gender were defined. When identical data sets were reported in more than one paper (for example Goelz et al., 2017, 2019), the record with the earliest publication date was selected. When subjects performed more than one task design within one publication, both were included into the meta-analysis as separate studies. Additionally, the references of all publications were screened to identify further studies that were missed by the literature search, which identified one new study. In total, 42 records fulfilled the inclusion criteria. Please see Fig. 1 for the flowchart for a complete overview of the search strategy.

Records were simultaneously screened for studies that reported results from the same PD group in two medication states or two STN-DBS states (on and off). Regarding levodopa, four papers with five studies were identified, including a total of 119 subjects for antisaccade latency and antisaccade error rate. Eight eligible STN-DBS studies were identified with a total of 66 subjects for antisaccade error rate and 89 subjects for antisaccade latency. We refrained from a meta-analysis of GPi-DBS effects as only two studies were identified for this DBS target.

\section{Data Extraction}

Data extraction and quality assessment were conducted by two independent investigators (LS, JSt or JS and JW). 
Fig. 1 Flowchart of the literature search procedure

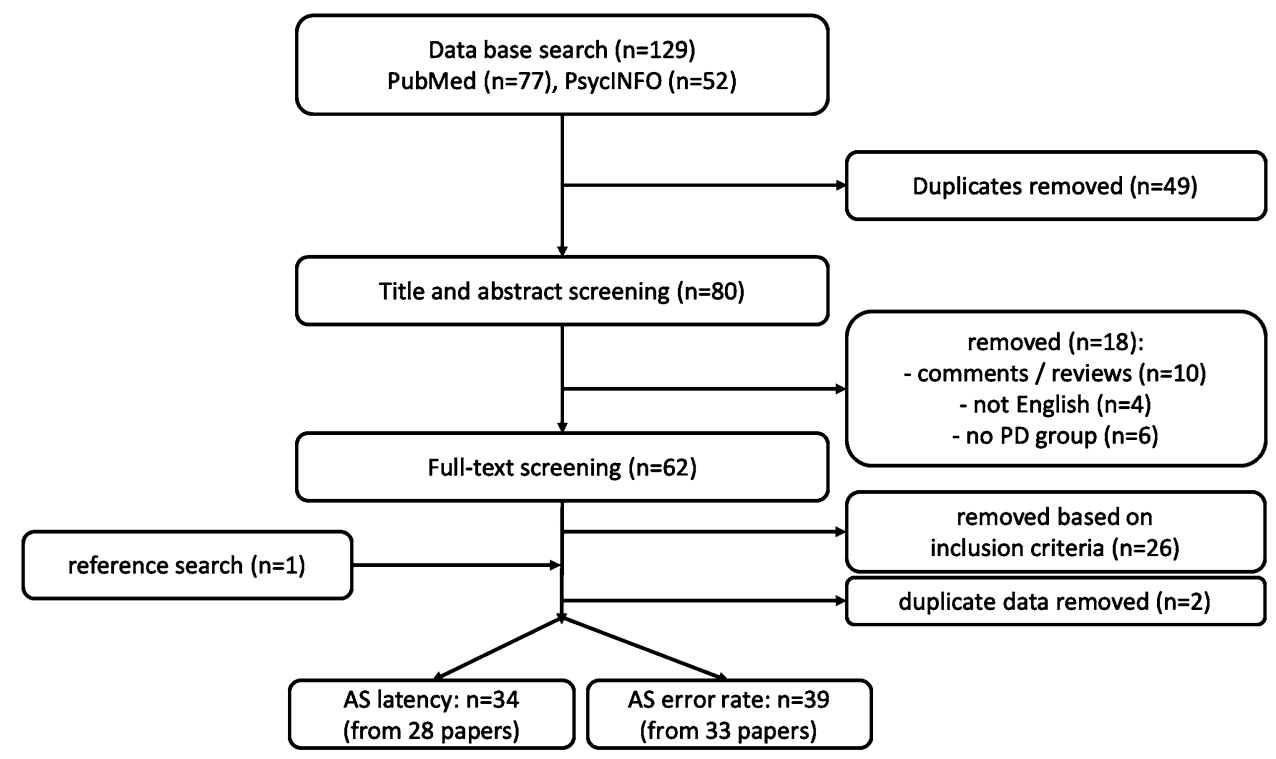

Besides mean and standard deviation (SD) of antisaccade error rate and antisaccade latency, the following information were extracted from each study: name of the first author, publication year, mean age, mean levodopa equivalent daily dosage, mean disease duration, mean Hoehn \& Yahr stage (Hoehn \& Yahr, 1967), mean Montreal Cognitive Assessment score (MoCA), mean Mini Mental State Examination score (MMSE), exclusion of PD-dementia, proportion of patients tested in on medication state.

The exclusion of dementia criterion was assigned when a) the study explicitly stated the exclusion of PD-dementia or b) the study used an MMSE or MoCA cut-off score to exclude cognitively impaired subjects, albeit we acknowledge that using a cut-off score of a global cognitive screening tool is not sufficient to accurately diagnose or exclude dementia. (Emre et al., 2014)

To acknowledge the potential impact of the large methodologic variety in task designs, several task-related factors were extracted: paradigm design (step, gap or overlap task; antisaccade-only task or randomly mixed task of antisaccades and visually-guided saccades within the same blocks), duration of fixations between trials (fixed or random duration), and target amplitude.

To account for the fact that several studies (36\%) included subsets of patients in on and off medication into the same group, medication state is reported as proportion of subjects in on medication state with a range from 0 (all patients were off levodopa for 12 hours or more) to one (all patients were tested after administration of dopaminergic medication). When a study provided results in on and off medication state, antisaccade latency, antisaccade error rates and the corresponding UPDRS scores or Hoehn \& Yahr stages in off state were included into the primary meta-analysis. When results were presented as figures, descriptive statistics were extracted using WebPlotDigitizer, version 4.2. (Rohatgi, 2015) For studies that did not provide mean or SD, but other descriptive statistics (i.e., median, minima and maxima or interquartile range), means and SD were estimated using the equations described by Hozo et al. (Hozo et al., 2005) When ranges were reported for the clinical measures, the mean of the range was used as an estimate.

\section{Statistical Analysis}

The meta-analyses and additional statistical analyses were performed using the metafor package (Viechtbauer, 2010) in R (R Core Team, 2014). Effect sizes, 95\% confidence intervals, variance, standard errors and statistical significance were calculated using a random-effects model. Effect sizes are reported as biased corrected standardized mean difference (Hedges' $g$ ) and were pooled across studies for obtaining an overall effect size using the inverse-variance method. To assess heterogeneity among studies, Cochran's Q and Higgins and Green's I ${ }^{2}$ statistics were computed. (HuedoMedina et al., 2006) Additionally, analysis of publication bias was performed since published studies may provide larger mean effect sizes than unpublished data. (Rothstein et al., 2006) Publication bias was visualized by funnel plots and symmetry, which was detected by Egger's test. (Egger et al., 1997) If a statistically significant publication bias was detected, the trim-and-fill method was used to adjust for the bias. (Duval \& Tweedie, 2000)

Meta-regressions were performed to assess the potentially important clinical and task-related moderators that might explain heterogeneity across the studies for which the respective information was available (see Table 2). MoCA was excluded from the moderator analysis on antisaccade latency because the score was available for less than 10 


\begin{tabular}{|c|c|c|c|c|c|c|c|c|}
\hline Study or & & PD & & & $\mathrm{HC}$ & & & Std. Mean Differenc \\
\hline Subgroup & Mean & SD & Total & Mean & SD & Total & Weight & IV, Random, $95 \%$ C \\
\hline Paradigm $=$ gap & & & & & & & & \\
\hline Bonnet 2014 & 0.52 & 0.29 & 21 & 0.23 & 30.20 & 27 & $2.8 \%$ & $1.17[0.55 ; 1.79]$ \\
\hline Bonnet 2014 (m) & 0.48 & 0.31 & 21 & 0.23 & 0.20 & 27 & $2.8 \%$ & $0.97[0.36 ; 1.57]$ \\
\hline Briand 1999 & 0.75 & 0.12 & 8 & 0.34 & 0.18 & 8 & $1.5 \%$ & $2.53[1.13 ; 3.94]$ \\
\hline Cameron 2012 & 0.23 & 0.18 & 13 & 0.10 & 0.07 & 13 & $2.4 \%$ & $0.92[0.11 ; 1.74]$ \\
\hline Chan 2003 & 0.19 & 0.03 & 18 & 0.19 & 0.02 & 18 & $2.7 \%$ & $0.00[-0.65 ; 0.65]$ \\
\hline Crawford 2013 & 0.24 & 0.17 & 25 & 0.18 & 0.13 & 18 & $2.8 \%$ & $0.38[-0.23 ; 0.99]$ \\
\hline Ewenczyk 2017 & 0.24 & 0.18 & 30 & 0.18 & 0.12 & 25 & $2.9 \%$ & $0.38[-0.16 ; 0.92]$ \\
\hline Hanuska 2019 & 0.49 & 0.25 & 18 & 0.24 & 0.20 & 25 & $2.7 \%$ & $1.10[0.45 ; 1.76]$ \\
\hline Hood 2007 & 0.50 & 0.23 & 14 & 0.21 & 0.19 & 14 & $2.4 \%$ & $1.33[0.50 ; 2.17]$ \\
\hline Machner 2010 & 0.51 & 0.22 & 14 & 0.26 & 0.16 & 27 & $2.6 \%$ & $1.35[0.63 ; 2.06]$ \\
\hline Nagai 2019 & 0.42 & 0.23 & 13 & 0.20 & 0.25 & 17 & $2.5 \%$ & $0.89[0.12 ; 1.65]$ \\
\hline Ranchet 2017 & 0.21 & 0.13 & 21 & 0.22 & 0.09 & 16 & $2.7 \%$ & $-0.09[-0.74 ; 0.57]$ \\
\hline Rivaud-Pechoux 2015 & 0.15 & 0.13 & 15 & 0.12 & 0.07 & 10 & $2.4 \%$ & $0.26[-0.54 ; 1.07]$ \\
\hline Rivaud-Pechoux 2015 (m) & 0.42 & 0.25 & 15 & 0.12 & 0.09 & 10 & $2.2 \%$ & $1.43[0.52 ; 2.34]$ \\
\hline van Koningsbruggen 2009 & 0.07 & 0.04 & 19 & 0.03 & 0.04 & 20 & $2.7 \%$ & $0.98[0.31 ; 1.65]$ \\
\hline van Stockum 2008 & 0.40 & 0.05 & 18 & 0.26 & 0.05 & 18 & $2.2 \%$ & $2.74[1.80 ; 3.67]$ \\
\hline Total $(95 \% \mathrm{Cl})$ & & & 283 & & & 293 & $40.3 \%$ & $0.94[0.61 ; 1.27]$ \\
\hline Heterogeneity: $\operatorname{Tau}^{2}=0.3037 ;$ & $\mathrm{Chi}^{2}=49$ & $19.48, \mathrm{~d}$ & if $=15$ & $P<0$ & 1); $; 1^{2}=7$ & & & \\
\hline Paradigm $=$ overlap & & & & & & & & \\
\hline Chan 2003 & 0.14 & 0.03 & 18 & 0.04 & 0.01 & 18 & $1.7 \%$ & $4.37[3.12 ; 5.63]$ \\
\hline Crawford 2013 & 0.26 & 0.18 & 25 & 0.12 & 0.10 & 18 & $2.7 \%$ & $0.90[0.27 ; 1.54]$ \\
\hline Hood 2007 & 0.35 & 0.20 & 14 & 0.11 & 0.15 & 14 & $2.4 \%$ & $1.32[0.49 ; 2.15]$ \\
\hline van Koningsbruggen 2009 & 0.11 & 0.13 & 19 & 0.06 & 0.09 & 20 & $2.7 \%$ & $0.44[-0.20 ; 1.08]$ \\
\hline Total $(95 \% \mathrm{Cl})$ & & & 76 & & & 70 & $9.5 \%$ & $1.65[0.39 ; 2.92]$ \\
\hline
\end{tabular}

Heterogeneity: Tau $^{2}=1.4729 ; \mathrm{Chi}^{2}=30.88$, df $=3(\mathrm{P}<0.01) ; \mathrm{I}^{2}=90 \%$

$\begin{array}{lrlllllll}\text { Paradigm = step } & & & & & & & & \\ \text { Amador 2005 } & 0.44 & 0.28 & 14 & 0.18 & 0.20 & 11 & 2.3 \% & 1.01[0.17 ; 1.86] \\ \text { Antoniades 2015 } & 0.15 & 0.03 & 30 & 0.09 & 0.02 & 25 & 2.6 \% & 2.28[1.59 ; 2.97] \\ \text { Barbosa 2019 } & 0.39 & 0.15 & 30 & 0.21 & 0.20 & 15 & 2.7 \% & 1.05[0.39 ; 1.71] \\ \text { Blekher 2009 } & 0.49 & 0.18 & 24 & 0.28 & 0.21 & 23 & 2.8 \% & 1.06[0.44 ; 1.67] \\ \text { Crevits 2000 } & 0.36 & 0.20 & 14 & 0.16 & 0.10 & 25 & 2.6 \% & 1.37[0.64 ; 2.10] \\ \text { Fukushima 1994 } & 0.25 & 0.19 & 22 & 0.04 & 0.05 & 20 & 2.6 \% & 1.45[0.76 ; 2.14] \\ \text { Gorges 2016 } & 0.56 & 0.25 & 31 & 0.28 & 0.18 & 22 & 2.8 \% & 1.23[0.63 ; 1.83] \\ \text { Khan 2019 } & 0.09 & 0.02 & 12 & 0.05 & 0.02 & 12 & 2.1 \% & 1.93[0.93 ; 2.93] \\ \text { Kitawaga 1994 } & 0.28 & 0.19 & 32 & 0.16 & 0.11 & 20 & 2.8 \% & 0.72[0.14 ; 1.30] \\ \text { Lemos 2016 } & 0.42 & 0.27 & 19 & 0.52 & 0.31 & 22 & 2.8 \% & -0.34[-0.95 ; 0.28] \\ \text { Lu 2019 } & 0.56 & 0.21 & 38 & 0.43 & 0.19 & 34 & 3.0 \% & 0.64[0.17 ; 1.12] \\ \text { Lueck 1990 } & 0.39 & 0.12 & 10 & 0.31 & 0.13 & 10 & 2.2 \% & 0.61[-0.29 ; 1.51] \\ \text { Mosimann 2005 } & 0.41 & 0.35 & 44 & 0.25 & 0.38 & 24 & 3.0 \% & 0.44[-0.06 ; 0.94] \\ \text { Nemanich 2016 } & 0.30 & 0.41 & 26 & 0.16 & 0.19 & 12 & 2.6 \% & 0.38[-0.31 ; 1.07] \\ \text { Querfelli-Ethier 2019 } & 0.31 & 0.26 & 20 & 0.32 & 0.25 & 22 & 2.8 \% & -0.04[-0.64 ; 0.57] \\ \text { van Stockum 2008 } & 0.42 & 0.06 & 18 & 0.25 & 0.06 & 18 & 2.2 \% & 2.77[1.83 ; 3.71] \\ \text { Waldthaler 2019 } & 0.35 & 0.27 & 40 & 0.18 & 0.17 & 20 & 2.9 \% & 0.69[0.14 ; 1.25] \\ \text { Walton 2015 } & 0.57 & 0.45 & 26 & 0.43 & 0.30 & 10 & 2.6 \% & 0.33[-0.40 ; 1.06] \\ \text { Wang 2016 } & 0.31 & 0.19 & 22 & 0.20 & 0.17 & 19 & 2.8 \% & 0.60[-0.03 ; 1.22] \\ \text { Total (95\% Cl) } & & & 472 & & & 364 & 50.2 \% & 0.92[0.61 ; 1.23]\end{array}$

Heterogeneity: $\mathrm{Tau}^{2}=0.3501 ; \mathrm{Chi}^{2}=75, \mathrm{df}=18(\mathrm{P}<0.01) ; \mathrm{I}^{2}=76 \%$

Total $(95 \% \mathrm{Cl})$

831

Prediction interval

Heterogeneity: $\mathrm{Tau}^{2}=0.3828 ; \mathrm{Chi}^{2}=157.74$, df $=38(\mathrm{P}<0.01) ; \mathrm{I}^{2}=76 \%$ Residual heterogeneity: $\mathrm{Tau}^{2}=\mathrm{NA} ; \mathrm{Chi}^{2}=155.36, \mathrm{df}=36(\mathrm{P}<0.01) ; 1^{2}=77 \%$
Std. Mean Difference

IV, Random, $95 \% \mathrm{CI}$

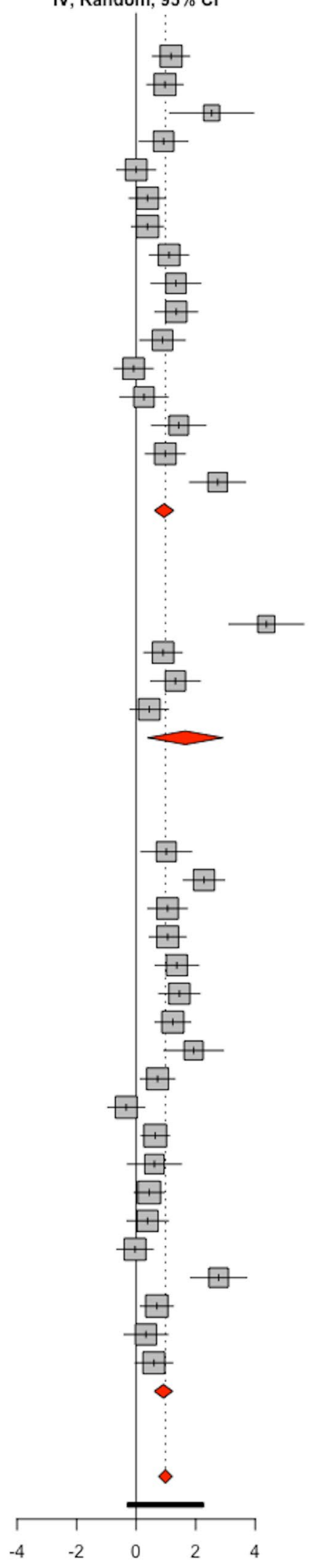


4Fig. 2 Forest plot for antisaccade error rate, sorted by paradigm with studies in alphabetical order. The size of the grey box represents the weight of the study in the meta-analysis. $C I$ confidence interval, $H C$ healthy control group, $P D$ group with Parkinson's disease, (m) mixed task design with prosaccades and antisaccades, $S D$ standard deviation, Std. standardized

studies. (Borenstein, 2009) Additionally, the differences between the PD group and healthy control group in age and MMSE score were used as indicators for the quality of the studies' matching procedure.

A $p$-value of $<0.05$ was set as the cut-off for significance in all analyses. P-values were adjusted using permutation tests with 1000 permutations implemented in the metafor package to address multiple testing in the meta-regressions. (Higgins \& Thompson, 2004) Here, the p-value for the model's coefficients equals the proportion of times that the absolute value of the test statistic for the coefficient under the permuted data is as extreme or more extreme than under the actually observed data. Permutation-based confidence intervals of the model coefficients were calculated by computationally shifting the observed effect sizes to find the most extreme values for which the permutation test leads to non-rejection.

Two separate meta-analyses were conducted using an identical approach to calculate overall effect sizes of levodopa medication for studies in which the same patient population was tested in on and off medication state, respectively on and off DBS state.

\section{Results}

\section{Demographic and Clinical Characteristics of the Study Samples}

The main characteristics of the selected studies are shown in Table 1. The total sample size was 703 patients with PD and 600 healthy control for antisaccade latency $(k=34)$, respectively 831 patients and 727 healthy control for antisaccade error rate $(k=39)$. Mean ages comprised between 52 and 77 years, with mean disease duration between 0.7 and 14.7 years and mean UPDRS III scores ranging from five to 85 .

$61 \%$ of studies considered PD-dementia an exclusion criterion, while $14 \%$ did not include any statement regarding the handling of cognitive impairment. Out of the 24 studies specifically excluding demented subjects, nine studies did not report the exact clinical criteria for diagnosis of dementia and 15 used a cut-off score of a global cognitive screening test (MMSE or MoCA). Only one study explicitly included a proportion of $50 \%$ patients with PD-dementia. (Mosimann et al., 2005) Exploratory exclusion of this study from further analysis did not change the results of this meta-analysis.

\section{Meta-Analysis: Antisaccade Error Rate}

The PD group showed a significantly higher error rate $(0.34$, $95 \%$-CI $=[0.30 ; 0.39])$ than the healthy control group $(0.19$, $95 \%-\mathrm{CI}=[0.16 ; 0.22])$ with an overall effect size of 0.99 $(k=39,95 \%$-CI $=[0.76 ; 1.21], t=8.52, p<0.0001)$.

The prediction interval indicates that $95 \%$ of future studies may find an effect size ranging between -0.29 and 2.26 based on the results of the studies included in this meta-analysis (Fig. 2).

Heterogeneity between studies was high $\left(\mathrm{I}^{2}=75.9 \%\right.$, 95\%-CI $=[67.3 \% ; 82.3 \%] ; \mathrm{H}=2.04,95 \%-\mathrm{CI}=[1.75 ; 2.37]$, $\mathrm{Q}(\mathrm{df}=38)=157.7, p<0.0001)$, and Egger's test was significant (intercept 6.017, $\mathrm{t}=4.64, \mathrm{p}<0.0001$ ). Therefore, nine virtual studies were added using the trim-and-fill-method which resulted in a persisting significant effect of PD on the antisaccade error rate $(k=48, \mathrm{~g}=0.68,95 \%-\mathrm{CI}=[0.42$; 0.93 ], $t=5.14 p<0.0001$, see Supplementary Material for the funnel plot).

\section{Meta-Analysis: Antisaccade Latency}

PD had a significantly prolonging effect on antisaccade latency with an effect size of $0.84(k=34,95 \%$-CI $=[0.52$; 1.15] $t=5.24, p<0.0001$ ) (Fig. 3). Based on the calculated prediction interval, $95 \%$ of future studies may find an effect size ranging between -0.90 and 2.58 (Fig. 3).

Heterogeneity between studies was high $\left(\mathrm{I}^{2}=84.8 \%\right.$ 95\%-CI=[79.7\%; 88.6\%]; $\mathrm{H}=2.56,95 \%-\mathrm{CI}=[2.22 ; 2.96]$; $\mathrm{Q}(\mathrm{df}=33)=216.8, p<0.0001)$ and Egger's test was significant (intercept $6.038 \mathrm{t}=4.225, \mathrm{p}<0.0001$ ). After adding seven virtual studies using the trim-and-fill-method, the effect remained significant $(k=41, \mathrm{~g}=0.41,95 \%-\mathrm{CI}=[0.059 ; 0.77]$, $t=2.29, p=0.02$, see Supplementary Material for the funnel plot). The mean latency was $339.8 \mathrm{~ms}$ in the PD group and $294.2 \mathrm{~ms}$ in the healthy control group in the gap paradigm, respectively $411.7 \mathrm{~ms}$ in the PD group and $368.6 \mathrm{~ms}$ in the healthy control group in the step paradigm.

\section{Moderator Analysis}

Meta-regressions revealed that disease duration, Hoehn \& Yahr stage and UPDRS III score were mediators of the effect of PD on antisaccade latency (Fig. 4a). PD patients with more severe disease burden executed antisaccades with increasingly higher latency compared to the healthy control group. UPDRS III and disease duration accounted for $26 \%$, respectively $7 \%$ of the heterogeneity across studies.

The levodopa-equivalent daily dosage showed a trend towards a negatively moderating effect on antisaccade error rate with a statistical significance at the cut-off value ( $p=0.05$ ). (Fig. $4 \mathrm{~b})$. See Table 2 for the results of all meta-regressions. 


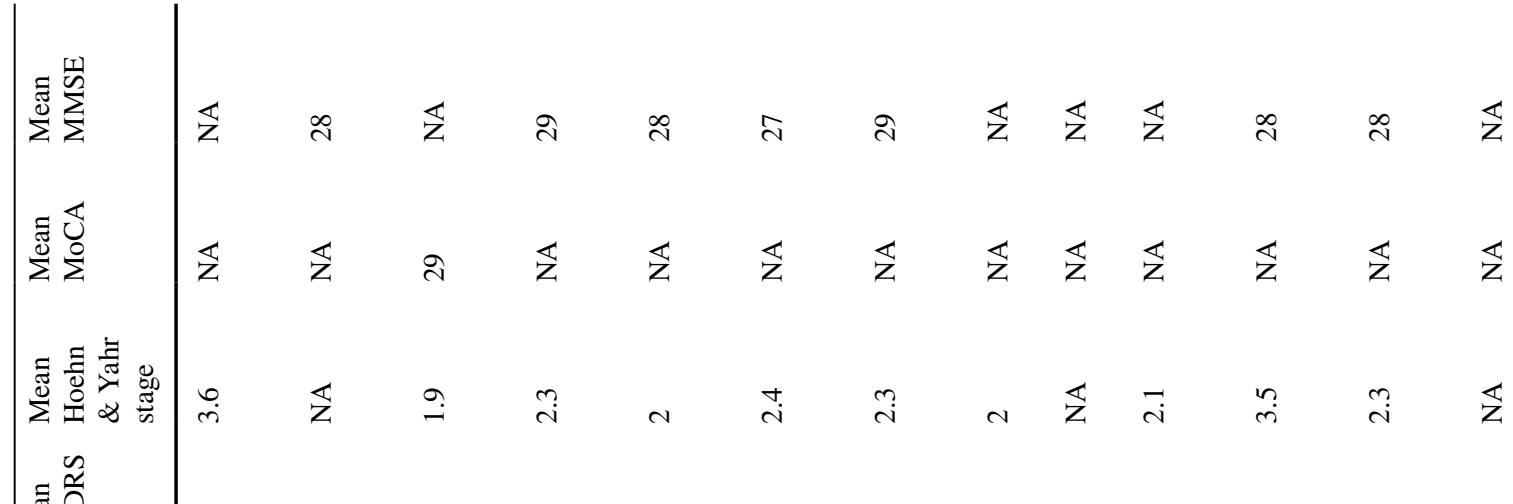

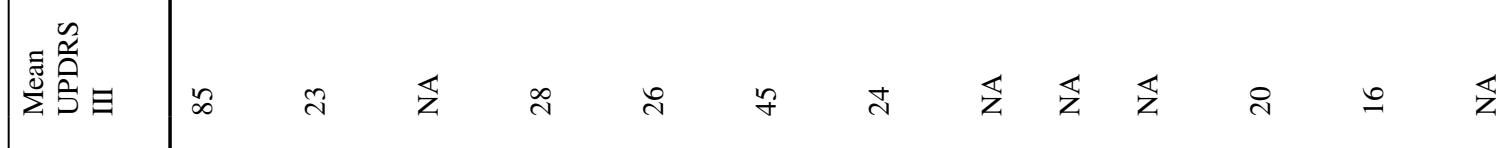

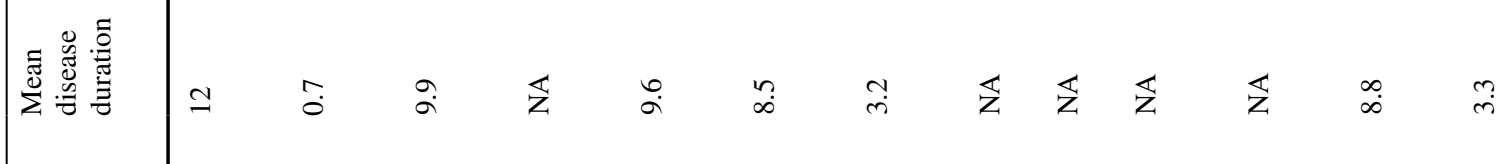

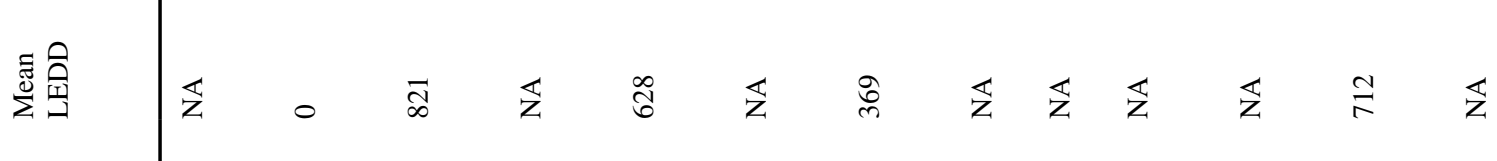

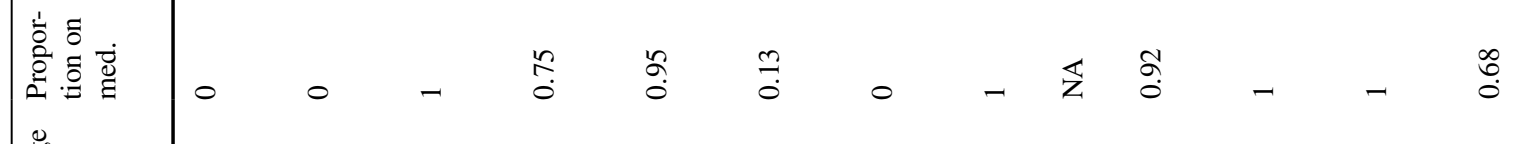

$$
\begin{aligned}
& \text { ( }
\end{aligned}
$$

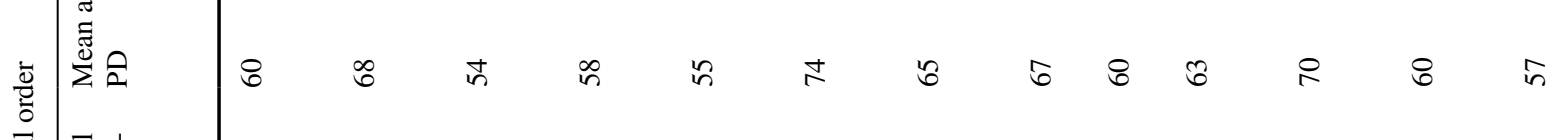

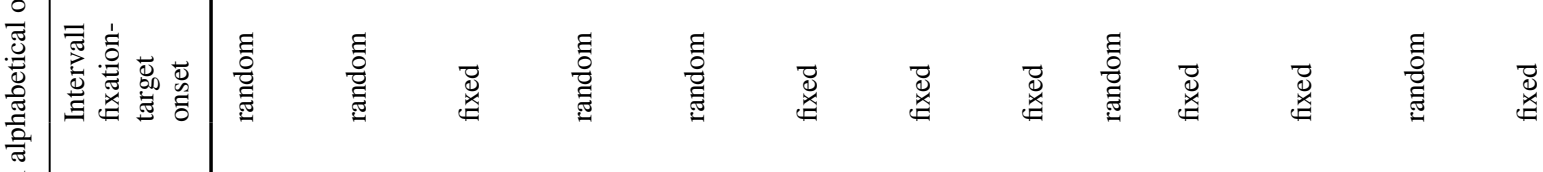

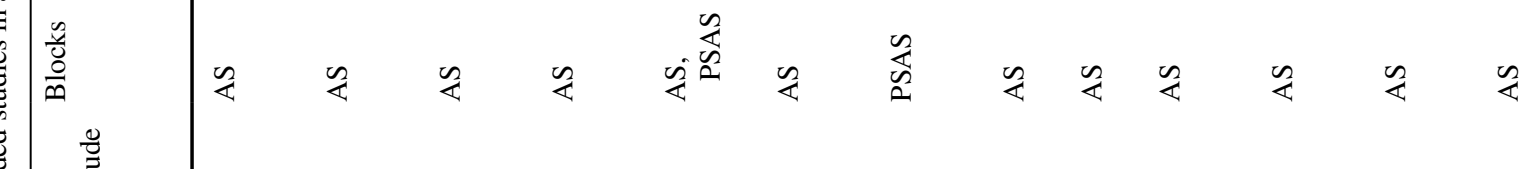

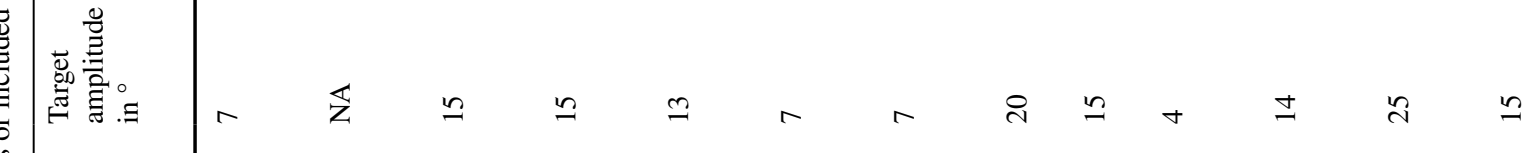

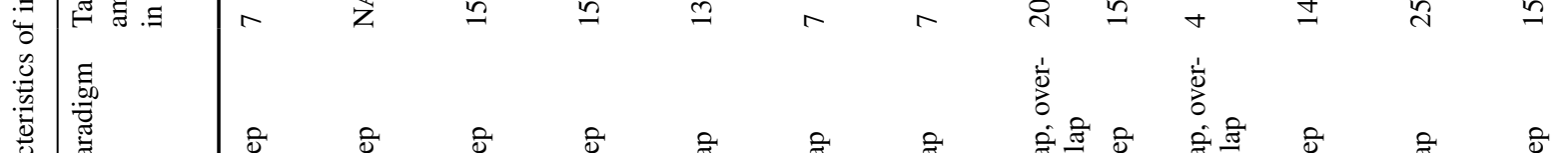

$$
\begin{aligned}
& \text { 莺 }
\end{aligned}
$$

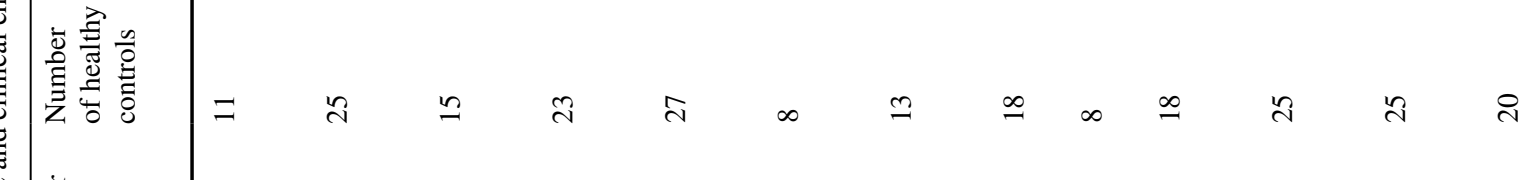

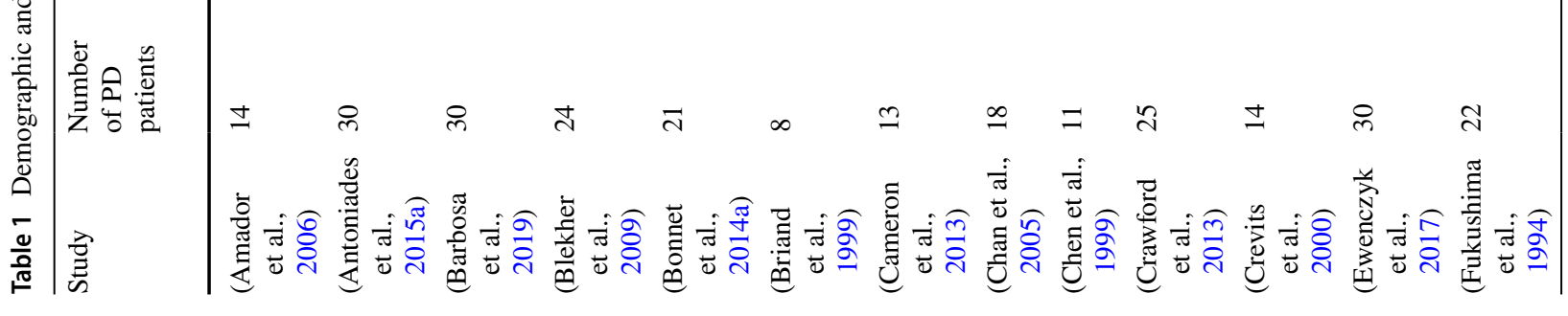




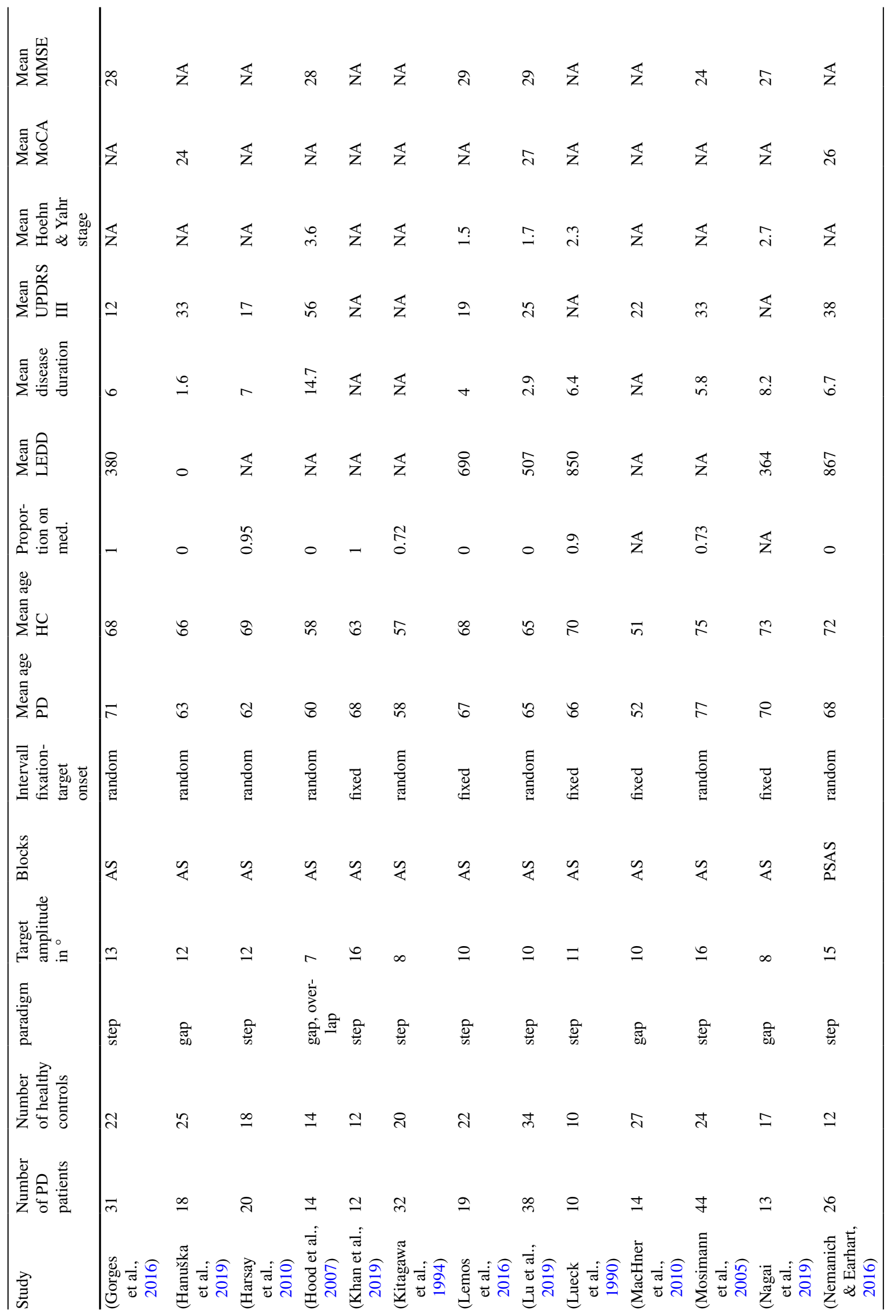


Neuropsychology Review (2021) 31:628-642

635

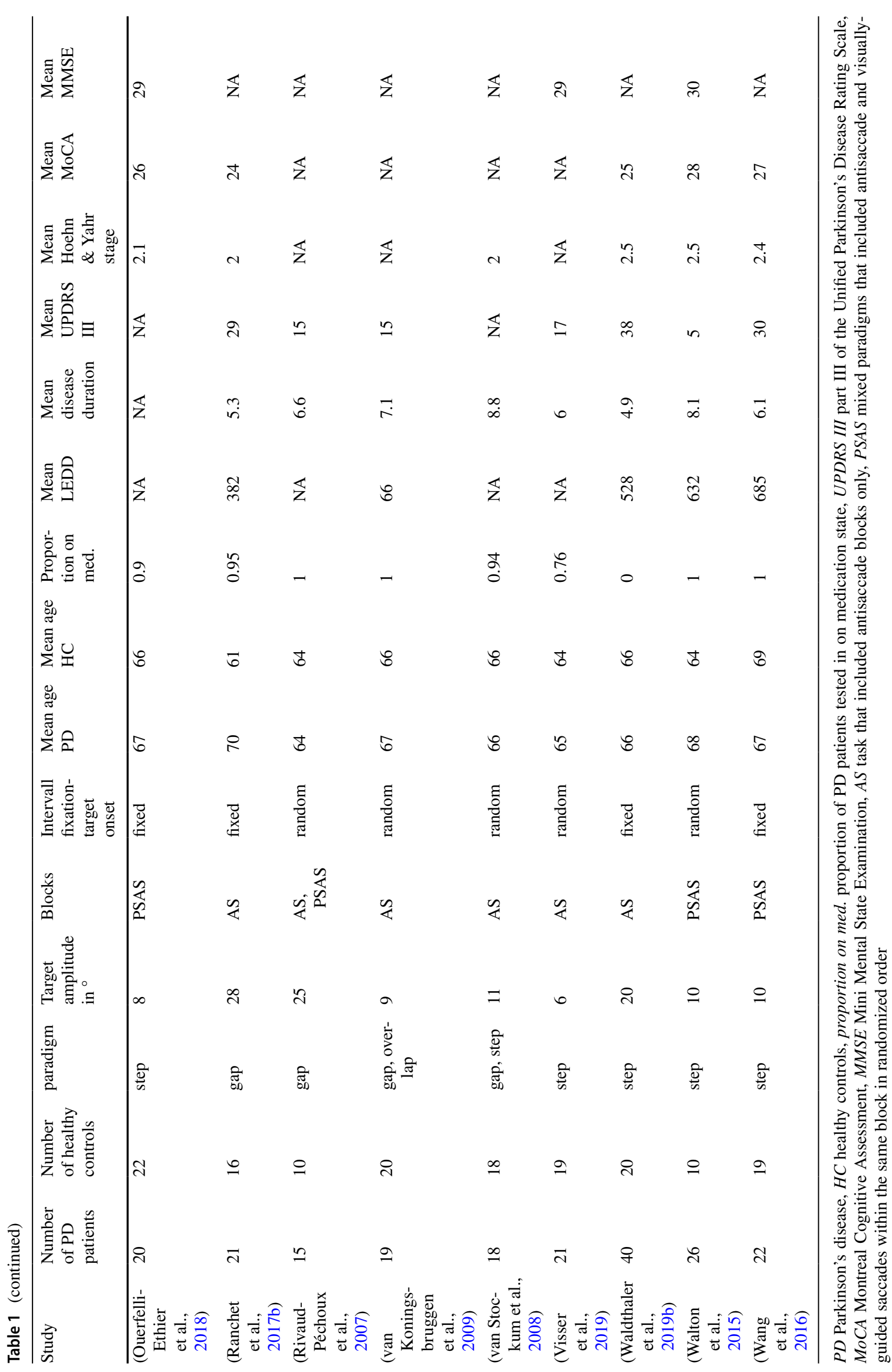

Springer 


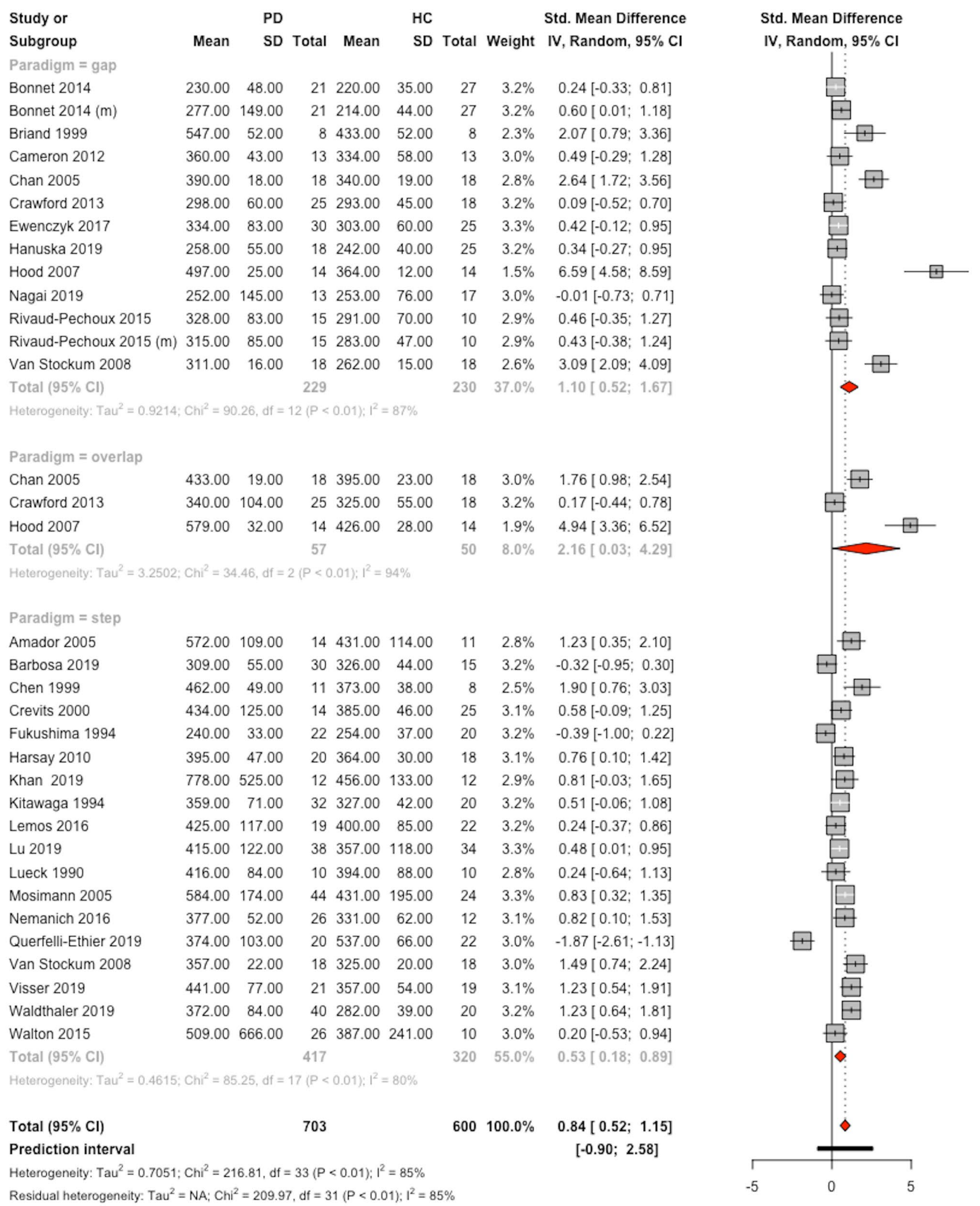

Fig. 3 Forest plot for antisaccade latency, sorted by paradigm with studies in alphabetical order. The size of the grey box represents the weight of the study in the meta-analysis. $\mathrm{CI}$ confidence interval, $\mathrm{HC}$ healthy control group, $P D$ group with Parkinson's disease, $(m)$ mixed task design with prosaccades and antisaccades, $S D$ standard deviation, Std. standardized 


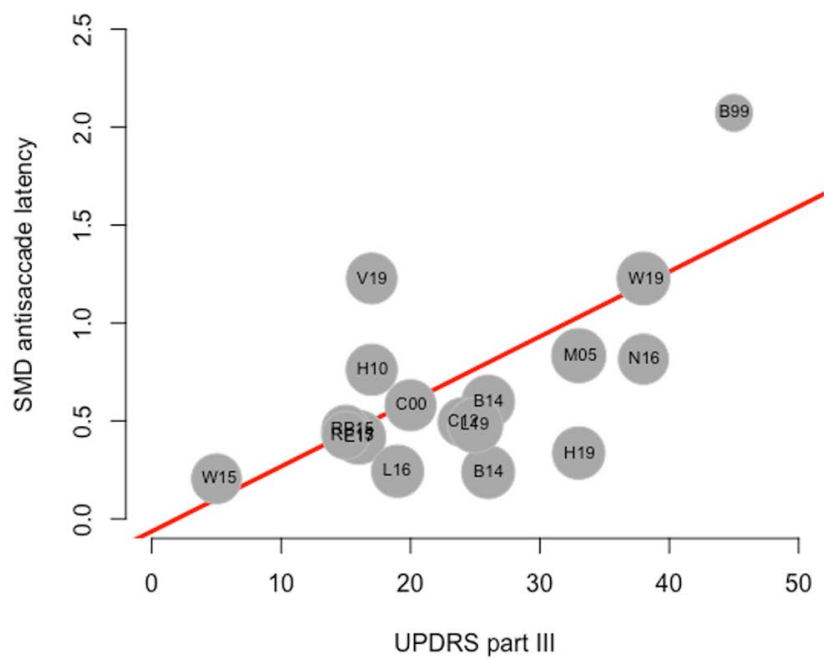

Fig. 4 Bubble plots of the mediating / moderating effects of A: mean UPDRS III score on antisaccades latency and B: mean LEDD on antisaccades error rate. B99 (Briand et al., 1999), B14 (Bonnet et al., 2014b), B19 (Barbosa et al., 2019), C12 (Cameron et al., 2012), COO (Crevits et al., 2000), E17 (Ewenczyk et al., 2017), G16 (Gorges et al., 2016), H10 (Harsay et al., 2010), H19 (Hanuška et al.,

\section{Meta-Analysis of Levodopa Effect on Antisaccade Performance}

There was no significant effect of levodopa administration on antisaccade latency $((k=5, \mathrm{~g}=0.07,95 \%-\mathrm{CI}=[-0.37$;

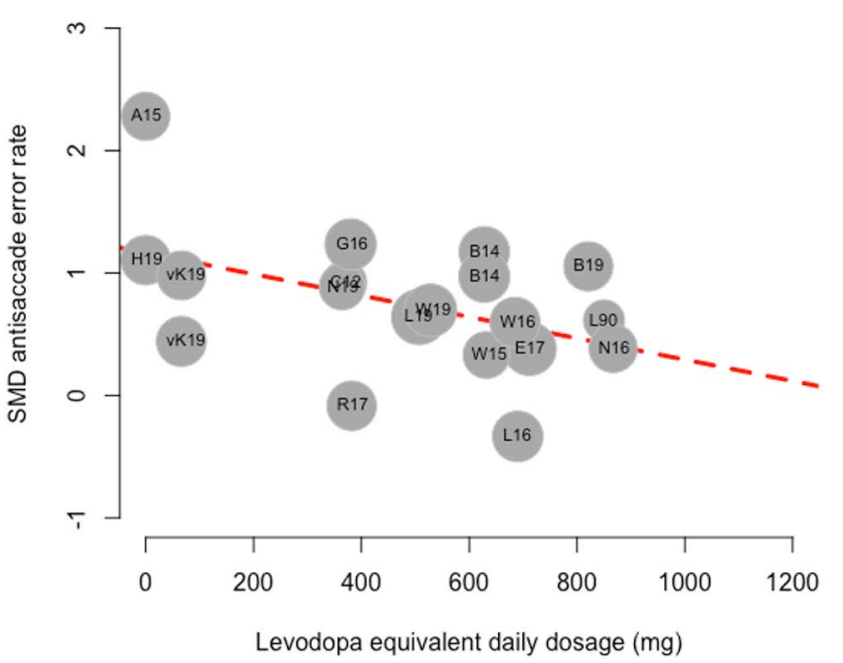

2019), L19 (Lu et al., 2019), L90 (Lueck et al., 1990), L16 (Lemos et al., 2016), M05 (Mosimann et al., 2005), N16 (Nemanich \& Earhart, 2016), N19 (Nagai et al., 2019), R17 (Ranchet et al., 2017), RP15 (Rivaud-Péchoux et al., 2007), V19 (Visser et al., 2019), $v K 09$ (van Koningsbruggen et al., 2009), W15 (Walton et al., 2015), W16 (Wang et al., 2016), W19 (Waldthaler et al., 2019a)

$0.52], t=0.32, p=0.7)$. or error rate $((k=5, \mathrm{~g}=-0.13,95 \%$-CI $=[-0.39 ; 0.12], t=-1.01, p=0.3)$ based on the five eligible studies (Fig. 5a, b) with considerable heterogeneity $\left(\mathrm{I}^{2}=\right.$ $62.7 \%, 95 \%-\mathrm{CI}=[1.2 \% ; 85.9 \%] ; \mathrm{H}=1.64,95 \%-\mathrm{CI}=[1.01$; 2.66]; $\mathrm{Q}(\mathrm{df}=4)=10.72, p=0.03)$. Heterogeneity measures

Table 2 Results of the meta-regressions with permutation test-adjusted p-values and confidence intervals

\begin{tabular}{|c|c|c|c|c|c|c|c|c|c|c|c|c|}
\hline \multirow[b]{2}{*}{ Moderator } & \multicolumn{6}{|c|}{ Antisaccade error rate } & \multicolumn{6}{|c|}{ Antisaccade latency } \\
\hline & $\mathrm{k}$ & $\mathrm{R}^{2}$ & beta & $\min 95 \% \mathrm{CI}$ & $\max 95 \% \mathrm{CI}$ & $\mathrm{p}$ & $\mathrm{k}$ & $\mathrm{R}^{2}$ & beta & $\min 95 \% \mathrm{CI}$ & $\max 95 \% \mathrm{CI}$ & $\mathrm{p}$ \\
\hline age difference PD-HC & 39 & 0 & 0.01 & -0.04 & 0.052 & 0.69 & 34 & 0 & 0.01 & -0.07 & 0.07 & 0.79 \\
\hline MMSE difference PD- HC & 14 & 1.8 & -0.11 & -0.20 & 0.45 & 0.45 & 12 & 0 & 0.19 & -0.24 & NA & 0.50 \\
\hline proportion on medication & 37 & 0 & 0.00 & -0.58 & 0.69 & 0.99 & 32 & 0 & -0.78 & -1.67 & 0.20 & 0.11 \\
\hline age PD group & 39 & 0 & -0.01 & -0.05 & 0.04 & 0.72 & 34 & 0 & 0.00 & -0.09 & 0.08 & 0.99 \\
\hline levodopa-equivalent daily dose & 19 & 22.0 & -0.00 & -0.00 & 0.00 & 0.05 & 13 & 0 & 0.00 & -0.00 & 0.00 & 0.78 \\
\hline disease duration & 29 & 0 & 0.03 & -0.06 & 0.11 & 0.45 & 25 & 6.9 & 0.22 & 0.10 & 0.37 & 0.001 \\
\hline UPDRS III & 26 & 0 & 0.01 & -0.01 & 0.02 & 0.30 & 20 & 25.8 & 0.03 & 0.01 & 0.06 & 0.01 \\
\hline Hoehn \& Yahr stage & 26 & 2.9 & 0.33 & -0.54 & 0.79 & 0.48 & 23 & 2.2 & 1.15 & 0.04 & 2.31 & 0.02 \\
\hline $\mathrm{MoCA}$ & 10 & 0 & 0.07 & -0.14 & 0.28 & 0.42 & 8 & NA & NA & NA & NA & NA \\
\hline MMSE & 17 & 1.6 & -0.15 & -0.39 & 0.12 & 0.25 & 15 & 0 & -0.18 & -0.85 & 0.64 & 0.54 \\
\hline exclusion of PD-dementia & 39 & 0 & 0.28 & -0.39 & 0.64 & 0.66 & 34 & 0 & -0.07 & -0.86 & 0.79 & 0.87 \\
\hline mixed blocks (AS+PS) & 39 & 0.6 & -0.43 & -1.20 & 0.16 & 0.17 & 34 & 2.4 & -0.88 & -1.96 & 0.02 & 0.08 \\
\hline fixation intervall & 39 & 0 & 0.15 & -0.37 & 0.68 & 0.57 & 34 & 3.0 & 0.66 & -0.14 & 1.46 & 0.09 \\
\hline overlap paradigm & 39 & 0 & 0.55 & -0.44 & 1.53 & 0.29 & 34 & 0 & 0.82 & -0.89 & 2.53 & 0.28 \\
\hline step paradigm & 39 & 0 & -0.03 & -0.61 & 0.55 & 0.91 & 34 & 0 & -0.53 & -1.46 & 0.41 & 0.32 \\
\hline target amplitude & 38 & 0 & -0.01 & -0.05 & 0.03 & 0.64 & 34 & 0 & -0.00 & -0.09 & 0.06 & 0.91 \\
\hline
\end{tabular}

$k$ number of studies included in the meta-regression analysis, $P D$ Parkinson's disease, $H C$ healthy controls, proportion on med proportion of PD patients tested in on medication state, UPDRS III part III of the Unified Parkinson's Disease Rating Scale, MoCA Montreal Cognitive Assessment, MMSE Mini Mental State Examination, mixed blocks paradigm that included antisaccades and visually-guided saccades in the same task in randomized order 
a

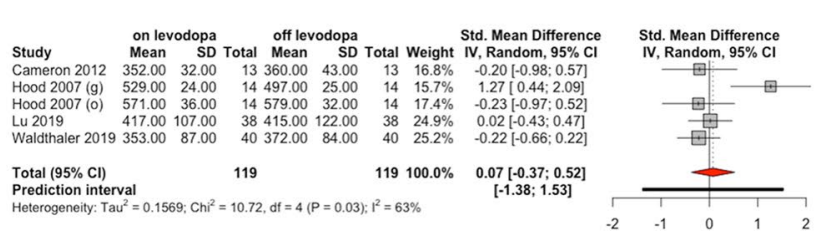

b

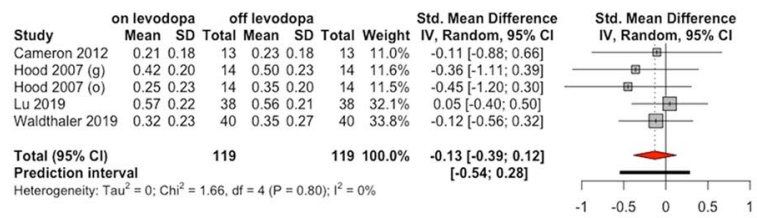

Fig. 5 Forrest plots of the effect of levodopa (a and $\mathbf{b})$ and STN-DBS (c and d) on antisaccade latency (a and $\mathbf{c}$ ) and error rate (b and d). Negative Hedge's g values indicate a favor for the on medication /

were low for error rates $\left(\mathrm{I}^{2}=0.0 \%, 95 \%\right.$-CI $=[0.0 \% ; 49.8 \%]$; $\mathrm{H}=1.00,95 \%-\mathrm{CI}=[1.00 ; 1.41] ; \mathrm{Q}(\mathrm{df}=4)=1.66, p=0.8)$.

\section{Meta-Analysis of STN DBS Effect on Antisaccade Performance}

Switching STN-DBS on had a significantly reducing effect on antisaccade latency with an effect size of $-0.44 \quad(k=8$, $\mathrm{g}=0.44,95 \%-\mathrm{CI}=[-0.7729 ;-0.0994] t=-2.54, p=0.01)$ based on 8 eligible studies (Fig. $5 \mathrm{c}$ ) with low heterogeneity $\left(\mathrm{I}^{2}\right.$ $=12.6 \% 95 \%-\mathrm{CI}=[0 \% ; 55.0 \%] ; \mathrm{H}=1.07,95 \%-\mathrm{CI}=[1.00$; 1.49]; $\mathrm{Q}(\mathrm{df}=7)=8.01, \mathrm{p}=0.3)$. There was a trend towards higher antisaccade error rates in DBS-on state with an effect size of 0.50 , however, without reaching statistical significance based on 5 eligible studies $(k=5, \mathrm{~g}=0.50,95 \%$-CI $=[-1.2638 ; 2.2617] t=1.7, p=0.09)$ with considerable heterogeneity $\left(\mathrm{I}^{2}=53.5 \% 95 \%-\mathrm{CI}=[0 \% ; 82.9 \%] ; \mathrm{H}=1.47\right.$, 95\%-CI=[1.00; 2.42]; $\mathrm{Q}(\mathrm{df}=4)=8.6, p=0.07)$ (Fig. 5d).

\section{Discussion}

This is the first meta-analysis exploring alterations of antisaccade performance in PD, which confirms significant higher antisaccade error rates and increased antisaccade latency in PD. Variables representing motor disease severity, i.e. disease duration, UPDRS III score, and Hoehn \& Yahr stage mediate the effect, with a higher motor burden and disease duration being associated with prolonged antisaccade latency. Thus, antisaccade latency may provide a potential marker of disease severity in $\mathrm{PD}$, as has been proposed earlier in studies with smaller sample sizes.

The antisaccade task is a well-known proxy to examine the impairment of frontal-based cognitive functions

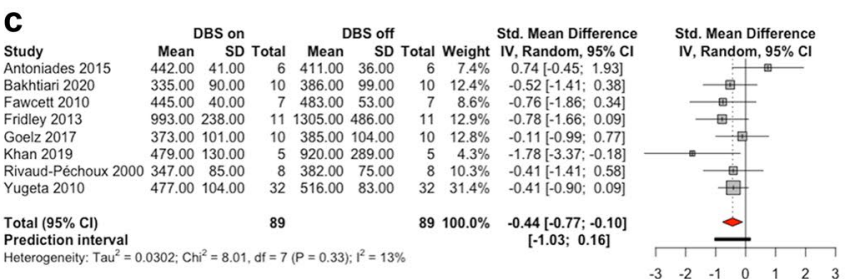

d

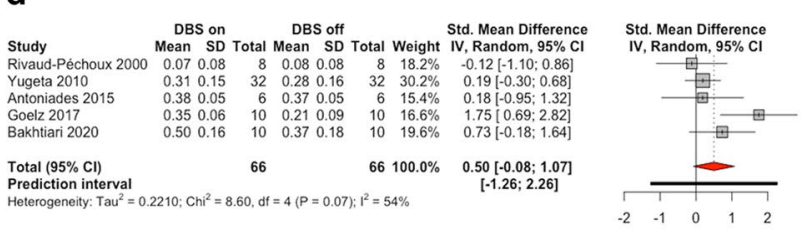

DBS state. $C I$ confidence interval, $(g)$ gap paradigm, $(m)$ mixed task design with prosaccades and antisaccades, $(o)$ overlap paradigm, Std. standardized

in numerous neurological diseases. Such impairment, including impaired response inhibition in the antisaccade task, is also an early symptom of PD that may even be present in the prodromal stage of the disease prior to the onset of motor symptoms. (Hogue et al., 2018) However, the dysexecutive syndrome may not be primarily caused by direct neuropathological involvement of the prefrontal cortex itself. Instead, decreased striatal dopaminergic stimulation may result in disrupted functional connectivity of fronto-striatal circuits. Early in the disease course of $\mathrm{PD}$, dopamine depletion is mainly evident in the dorsolateral striatum, i.e. the caudate nucleus, which is involved in a reciprocal loop with the dorsolateral prefrontal cortex (DLPFC). (Sawamoto et al., 2008) DLPFC has been shown to play a major role in inhibiting pre-potent responses in the direction of the visual target in the antisaccade task. (Hwang et al., 2016) Importantly, other cognitive functions, that are dependent on the integrity of the dorsolateral frontostriatal circuit, for example planning, task-switching and working memory, have been demonstrated to improve after levodopa administration. (Cools, 2006) Hence, a beneficial effect of dopaminergic medication is also conceivable for antisaccades. The separate meta-analysis of studies assessing antisaccades in off and on medication states within the same patients did not result in an overall effect of acute levodopa administration on antisaccades latency or error rate. The low number of four eligible publications was surprising, given the relatively large body of literature on antisaccade performance in PD overall.

Although phasic stimulation by levodopa administration did not have a significant effect, patients with higher chronic dopaminergic medication tended to make lower numbers of reflexive errors in the antisaccade task. If the levodopa equivalent dosage was interpreted as a proxy for disease severity in this context, the opposite association 
might have been expected. Instead, a potential association of higher daily dosages with lower antisaccade error rates may be interpreted as indirect evidence that levodopa may have an improving effect on antisaccade performance. However, this assumption remains speculative, since the analysis of the levodopa-equivalent daily dosage as a moderator of antisaccade error rate did not reach statistical significance.

Chronic dopaminergic stimulation may improve the dorsolateral fronto-striatal circuit in the long term and substances with long half-lives may have influenced the results of studies in off medication state. Dopamine-agonists in particular have long half-lives that may exceed the 12-hours withdrawal interval used in many studies. Furthermore, differences in the pharmacokinetic profiles of levodopa and dopamine-agonists as well as their distinct affinities for dopamine receptor subtypes may also differentially influence antisaccade performance. As such, dopamine-agonist intake may have a higher potential for increased motor response impulsivity which may result in higher antisaccade error rates. (Claassen et al., 2015) Since only a very small proportion of studies reported the exact composition of medications contributing to the levodopa equivalent daily dosage, it was not feasible to compare the effect of the different medications in this meta-analysis. More research is warranted to conclusively determine the effect of different dopaminergic drugs as well as other symptomatic medications (e.g. cholinergics, amantadine, acetylcholinesterase inhibitors) in PD. This may become particularly important in the evaluation of antisaccades latency as a marker for disease progression that would be most useful if it was not influenced by any external dopaminergic stimulation.

Until today, no study was published that reported changes of antisaccade performance in PD longitudinally. Such data would be crucial to explore the slope of antisaccade latency and error rate changes in individual patients and to evaluate the value of antisaccade latency as a marker for disease progression, for instance in upcoming clinical trials of potentially disease-modifying therapies.

As opposed to the inconclusive results regarding levodopa, STN-DBS had a significant effect on antisaccades, as switching on DBS decreased antisaccade latency which is in line with a review by Terao et al. who hypothesized that dopaminergic medication and DBS may alter saccades via distinct mechanisms. (Terao et al., 2013) That PD patients executed antisaccades faster when STN-DBS was switched on with an increased probability of errors indicates towards a shift in the speed-accuracy trade-off, i.e. an increase in motor impulsivity with STNDBS. Generally speaking, the STN may serve as a proactive "brake" for reflexive responses of various modalities and thus, seem to play a crucial role in response inhibition. (Jahanshahi et al., 2015) In a study of local field potentials in the STN of patients with PD during DBS surgery, saccade-related beta band desynchronization during preparation of an antisaccade was stronger and longer preceding the execution of a correct antisaccade than an error. (Yugeta et al., 2013) While suppression of pathologically enhanced synchronization of beta oscillations in the sensorimotor circuits between cortex, basal ganglia and thalamus is thought to lead to the improvement of bradykinesia with STN-DBS (Little et al., 2013), the same mechanism may also result in increased motor impulsivity via the hyperdirect pathway. (Jahanshahi, 2013) Whether different locations of the DBS electrodes within STN as well as other DBS targets, such as GPi, may result in variable effects on antisaccade performance, should be investigated in future research.

Given that the course of PD and many of its symptoms are very heterogenous (Fereshtehnejad et al., 2017), the disease burden may vary substantially not only between studies, but also between subjects within the cohort. Presence and progression of cognitive impairment especially, which are highly variable between patients, have a huge impact on the overall long-term outcome. (Aarsland et al., 2004) A major limitation of this meta-analysis is that the effect of cognitive impairment on antisaccade performance could not be sufficiently evaluated based on the published literature. While several studies have provided robust evidence that antisaccade error rate is associated with executive dysfunction in healthy individuals (Hellmuth et al., 2012) and PD patients (Ouerfelli-Ethier et al., 2018), global cognitive scores did not moderate the effect of PD on antisaccade error rate or latency in this meta-analysis. MoCA and MMSE were reported infrequently in $24 \%$, respectively $43 \%$ of the studies and many of those included varying cut-offs to exclude patients with cognitive impairment. Moreover, $61 \%$ of studies excluded patients with signs of dementia using various different diagnostic criteria. A ceiling effect may also serve as a potential explanation for the lack of a moderating effect of MoCA and MMSE on antisaccade measures in this metaanalysis. More studies with comprehensive neuropsychological assessment may provide deeper understanding of correlations between dysfunction in different cognitive domains and their consequences on antisaccades in PD.

The criteria and rigor by which matching healthy control subjects are selected might not only influence the effect size of a study but is also an indicator of its quality. In our moderator analysis, neither the group difference in age nor in the MMSE score moderated the effect of PD on the antisaccade measures. However, the validity of the finding is limited by the low proportion of $46 \%$ of studies reporting at least one cognitive score for the control group. Thus, one must assume that the majority of studies did not take measures to match subjects based on general cognitive ability or educational attainment which might have resulted in a selection bias, likely to the disadvantage of the PD group.

Although the meta-regressions did not support a moderating effect of any of the variables related to task design, the methodological heterogeneity of antisaccade studies still 
hampers straight-forward interpretation and comparison between studies. As shown in Table 1, study protocols have varied largely in several factors, for some of which an impact on performance has been reported. For example, mixing proand antisaccades within the same block adds a set shifting component to the task that may lead to an increase in antisaccade errors (Rivaud-Péchoux et al., 2007) and smaller target amplitudes may result in higher rates of express saccades, as supported by a recent meta-analysis of visually-guided saccades in PD. (Chambers \& Prescott, 2010) There is an obvious need for standardization of study protocols, not only in the field of PD research. Antoniades et al. proposed a standardized antisaccade protocol in 2013 (Antoniades et al., 2013) and we encourage researchers to be guided by this proposal.

Future studies on antisaccades in PD should include sufficient clinical characteristics to ensure quality and comparability between studies, among which disease duration, levodopa equivalent dosage, a global cognitive screening score (preferably MoCA (Hoops et al., 2009)), and Hoehn \& Yahr stage or, preferably UPDRS as a measure of motor disease severity may be minimum requirements. Furthermore, we want to emphasize the crucial role for careful selection of appropriate, task-naive control subjects.

In summary, this meta-analysis confirms altered antisaccade performance in PD with prolonged latency and increased error rates on a group level. While levodopa did not have a significant effect on antisaccades in a relatively small number of eligible studies, higher dosages of chronic dopaminergic medication may have a beneficial effect on antisaccade errors. In contrast, STN-DBS results in a speed accuracy trade-off, which may be indicative of increased motor impulsivity following STN-DBS in PD. The usefulness of antisaccade latency as a promising marker of motor severity in PD that may signify disease progression has to be further evaluated in longitudinal studies.

Supplementary Information The online version contains supplementary material available at https://doi.org/10.1007/s11065-021-09489-1.

Funding Open Access funding enabled and organized by Projekt DEAL. This work was supported by the German Federal Ministry of Education and Research [13GW0241, DIADEM, 2018].

\section{Declarations}

Competing interests Nothing to report.

Open Access This article is licensed under a Creative Commons Attribution 4.0 International License, which permits use, sharing, adaptation, distribution and reproduction in any medium or format, as long as you give appropriate credit to the original author(s) and the source, provide a link to the Creative Commons licence, and indicate if changes were made. The images or other third party material in this article are included in the article's Creative Commons licence, unless indicated otherwise in a credit line to the material. If material is not included in the article's Creative Commons licence and your intended use is not permitted by statutory regulation or exceeds the permitted use, you will need to obtain permission directly from the copyright holder. To view a copy of this licence, visit http://creativecommons.org/licenses/by/4.0/.

\section{References}

Aarsland, D., Andersen, K., Larsen, J. P., et al. (2004). The rate of cognitive decline in Parkinson disease. Archives of Neurology. https://doi.org/10.1001/archneur.61.12.1906

Amador, S. C., Hood, A. J., Schiess, M. C., et al. (2006). Dissociating cognitive deficits involved in voluntary eye movement dysfunctions in Parkinson's disease patients. Neuropsychologia. https:// doi.org/10.1016/j.neuropsychologia.2005.11.015

Antoniades, C., Ettinger, U., Gaymard, B., et al. (2013). An internationally standardised antisaccade protocol. Vision Research. https:// doi.org/10.1016/j.visres.2013.02.007

Antoniades, C. A., Demeyere, N., Kennard, C., et al. (2015a). Antisaccades and executive dysfunction in early drug-naive Parkinson's disease: The discovery study. Movement Disorders. https://doi. org/10.1002/mds.26134

Antoniades, C. A., Rebelo, P., Kennard, C., et al. (2015b). Pallidal deep brain stimulation improves higher control of the oculomotor system in parkinson's disease. The Journal of Neuroscience. https:// doi.org/10.1523/JNEUROSCI.2317-15.2015

Barbosa, P., Kaski, D., Castro, P., et al. (2019). Saccadic Direction Errors are Associated with Impulsive Compulsive Behaviours in Parkinson's Disease Patients. Journal of Parkinson's Disease, 9, 625-630. https://doi.org/10.3233/JPD-181460

Bari, A., \& Robbins, T. W. (2013). Inhibition and impulsivity: Behavioral and neural basis of response control. Progress in Neurobiology.

Blekher, T., Weaver, M., Rupp, J., et al. (2009). Multiple step pattern as a biomarker in Parkinson disease. Parkinsonism and Related Disorders Journal, 15, 506-510. https://doi.org/10.1016/j.parkreldis. 2009.01.002

Bonnet, C., Rusz, J., Megrelishvili, M., et al. (2014). Eye Movements in Ephedrone-Induced Parkinsonism. PLoS One, 9, e104784. https:// doi.org/10.1371/journal.pone.0104784

Bonnet, C., Rusz, J., Megrelishvili, M., et al. (2014). Eye movements in ephedrone-induced parkinsonism. PLoS One. https://doi. org/10.1371/journal.pone.0104784

Borenstein, M. (2009). Effect sizes for continuous data. In: The Hand. of Res. Synthesis and Meta-Analysis, 2nd Ed.

Briand, K. A., Strallow, D., Hening, W., et al. (1999). Control of voluntary and reflexive saccades in Parkinson's disease. Experimental Brain Research, 129, 38-48. https://doi.org/10.1007/s002210050934

Cameron, I. G. M., Brien, D. C., Links, K., et al. (2013). Changes to saccade behaviors in parkinson's disease following dancing and observation of dancing. Frontiers in Neurology. https://doi. org/10.3389/fneur.2013.00022

Cameron, I. G. M., Pari, G., Alahyane, N., et al. (2012). Impaired executive function signals in motor brain regions in Parkinson's disease. Neuroimage. https://doi.org/10.1016/j.neuroimage. 2012.01.057

Chambers, J. M., \& Prescott, T. J. (2010). Response times for visually guided saccades in persons with Parkinson's disease: A meta-analytic review. Neuropsychologia, 48, 887-899. https:// doi.org/10.1016/j.neuropsychologia.2009.11.006

Chan, F., Armstrong, I. T., Pari, G., et al. (2005). Deficits in saccadic eye-movement control in Parkinson's disease. Neuropsychologia. https://doi.org/10.1016/j.neuropsychologia.2004.06.026 
Chen, Y. F., Chen, T., \& Tsai, T. T. (1999). Analysis of volition latency on antisaccadic eye movements. Medical Engineering and Physics. https://doi.org/10.1016/S1350-4533(99)00082-X

Claassen, D. O., Van Den Wildenberg, W. P. M., Harrison, M. B., et al. (2015). Proficient motor impulse control in Parkinson disease patients with impulsive and compulsive behaviors. Pharmacology Biochemistry and Behavior. https://doi. org/10.1016/j.pbb.2014.11.017

Cools, R. (2006). Dopaminergic modulation of cognitive functionimplications for L-DOPA treatment in Parkinson's disease. Neuroscience and Biobehavioral.

Crawford, T. J., Higham, S., Mayes, J., et al. (2013). The role of working memory and attentional disengagement on inhibitory control: Effects of aging and Alzheimer's disease. Age (Omaha). https://doi.org/10.1007/s11357-012-9466-y

Crevits, L., Versijpt, J., Hanse, M., \& De Ridder, K. (2000). Antisaccadic effects of a dopamine agonist as add-on therapy in advanced Parkinson's patients. Neuropsychobiology. https://doi. org/10.1159/000026694

Duval, S., \& Tweedie, R. (2000). Trim and fill: A simple funnelplot-based method of testing and adjusting for publication bias in meta-analysis. Biometrics. https://doi.org/10.1111/j.0006341X.2000.00455.X

Egger, M., Smith, G. D., Schneider, M., \& Minder, C. (1997). Bias in meta-analysis detected by a simple, graphical test. British Medical Journal. https://doi.org/10.1136/bmj.316.7129.469

Emre, M., Ford, P. J., Bilgiç, B., \& Uç, E. Y. (2014). Cognitive impairment and dementia in Parkinson's disease: Practical issues and management. Movement Disorders.

Everling, S., \& Fischer, B. (1998). The antisaccade: A review of basic research and clinical studies. Neuropsychologia. https:// doi.org/10.1016/S0028-3932(98)00020-7

Ewenczyk, C., Mesmoudi, S., Gallea, C., et al. (2017). Antisaccades in Parkinson disease: A new marker of postural control? Neurology, 88, 853-861. https://doi.org/10.1212/WNL.0000000000003658

Fereshtehnejad, S. M., Zeighami, Y., Dagher, A., \& Postuma, R. B. (2017). Clinical criteria for subtyping Parkinson's disease: Biomarkers and longitudinal progression. Brain. https://doi. org/10.1093/brain/awx118

Fukushima, J., Fukushima, K., Miyasaka, K., \& Yamashita, I. (1994). Voluntary control of saccadic eye movement in patients with frontal cortical lesions and Parkinsonian patients in comparison with that in Schizophrenics. Biological Psychiatry. https://doi. org/10.1016/0006-3223(94)90058-2

Goelz, L. C., Cottongim, M., Metman, L. V., et al. (2019). Bilateral subthalamic nucleus deep brain stimulation increases fixational saccades during movement preparation: evidence for impaired preparatory set. Experimental Brain Research. https://doi. org/10.1007/s00221-019-05636-6

Goelz, L. C., David, F. J., Sweeney, J. A., et al. (2017). The effects of unilateral versus bilateral subthalamic nucleus deep brain stimulation on prosaccades and antisaccades in Parkinson's disease. Experimental Brain Research. https://doi.org/10.1007/s00221016-4830-2

Gorges, M., Müller, H. P., Lulé, D., et al. (2016). The association between alterations of eye movement control and cerebral intrinsic functional connectivity in Parkinson's disease. Brain Imaging and Behavior. https://doi.org/10.1007/s11682-015-9367-7

Hanuška, J., Rusz, J., Bezdicek, O., et al. (2019). Eye movements in idiopathic rapid eye movement sleep behaviour disorder: High antisaccade error rate reflects prefrontal cortex dysfunction. Journal of Sleep Research. https://doi.org/10.1111/jsr.12742

Harsay, H. A., Buitenweg, J. I. V., Wijnen, J. G., et al. (2010). Remedial effects of motivational incentive on declining cognitive control in healthy aging and Parkinson's disease. Frontiers in Aging Neuroscience. https://doi.org/10.3389/fnagi.2010.00144
Hellmuth, J., Mirsky, J., Heuer, H. W., et al. (2012). Multicenter validation of a bedside antisaccade task as a measure of executive function. Neurology. https://doi.org/10.1212/WNL.0b013e318258f785

Higgins, J. P. T., \& Thompson, S. G. (2004). Controlling the risk of spurious findings from meta-regression. Statistics in Medicine.

Hoehn, M. M., \& Yahr, M. D. (1967). Parkinsonism: Onset, progression, and mortality. Neurology. https://doi.org/10.1212/ wnl.17.5.427

Hogue, O., Fernandez, H. H., \& Floden, D. P. (2018). Predicting early cognitive decline in newly-diagnosed Parkinson's patients: A practical model. Parkinsonism and Related Disorders Journal. https:// doi.org/10.1016/j.parkreldis.2018.06.031

Hood, A. J., Amador, S. C., Cain, A. E., et al. (2007). Levodopa slows prosaccades and improves antisaccades: An eye movement study in Parkinson's disease. Journal of Neurology, Neurosurgery, and Psychiatry, 78, 565-570. https://doi.org/10.1136/jnnp.2006.099754

Hoops, S., Nazem, S., Siderowf, A. D., et al. (2009). Validity of the MoCA and MMSE in the detection of MCI and dementia in Parkinson disease. Neurology. https://doi.org/10.1212/ WNL.0b013e3181c34b47

Hozo, S. P., Djulbegovic, B., \& Hozo, I. (2005). Estimating the mean and variance from the median, range, and the size of a sample. BMC Medical Research Methodology. https://doi. org/10.1186/1471-2288-5-13

Huedo-Medina, T. B., Sánchez-Meca, J., Marín-Martínez, F., \& Botella, J. (2006). Assessing heterogeneity in meta-analysis: Q statistic or I 2 Index? Psychological Methods. https://doi. org/10.1037/1082-989X.11.2.193

Hwang, K., Ghuman, A. S., Manoach, D. S., et al. (2016). Frontal preparatory neural oscillations associated with cognitive control: A developmental study comparing young adults and adolescents. Neuroimage. https://doi.org/10.1016/j.neuroimage.2016.05.017

Jahanshahi, M. (2013). Effects of deep brain stimulation of the subthalamic nucleus on inhibitory and executive control over prepotent responses in parkinson's disease. Frontiers in System Neuroscience. https://doi.org/10.3389/fnsys.2013.00118

Jahanshahi, M., Obeso, I., Baunez, C., et al. (2015). Parkinson's disease, the subthalamic nucleus, inhibition, and impulsivity. Movement Disorders.

Khan, A. N., Bronstein, A., Bain, P., et al. (2019). Pedunculopontine and Subthalamic Nucleus Stimulation Effect on Saccades in Parkinson Disease. World Neurosurgery. https://doi.org/10.1016/j. wneu.2019.02.014

Kitagawa, M., Fukushima, J., \& Tashiro, K. (1994). Relationship between antisaccades and the clinical symptoms in parkinson's disease. Neurology. https://doi.org/10.1212/wnl.44.12.2285

Kudlicka, A., Clare, L., \& Hindle, J. V. (2011). Executive functions in Parkinson's disease: Systematic review and meta-analysis. Movement Disorders, 26, 2305-2315.

Leigh, R. J., Zee, D. S., Leigh, R. J., Zee, D. S. (2015). The Saccadic System. In: The Neurology of Eye Movements.

Lemos, J., Pereira, D., Almendra, L., et al. (2016). Distinct functional properties of the vertical and horizontal saccadic network in Health and Parkinson's disease: An eye-tracking and fMRI study. Brain Research, 1648, 469-484. https://doi.org/10.1016/j.brainres. 2016.07.037

Little, S., Pogosyan, A., Neal, S., et al. (2013). Adaptive deep brain stimulation in advanced Parkinson disease. Annals of Neurology. https://doi.org/10.1002/ana.23951

Lu, Z., Buchanan, T., Kennard, C., et al. (2019). The effect of levodopa on saccades - Oxford Quantification in Parkinsonism study. Parkinsonism and Related Disorders Journal. https://doi. org/10.1016/j.parkreldis.2019.09.029

Lueck, C. J., Tanyeri, S., Crawford, T. J., et al. (1990). Antisaccades and remembered saccades in Parkinson's disease. Journal of Neurology, Neurosurgery, and Psychiatry. https://doi.org/10.1136/ jnnp.53.4.284 
MacHner, B., Klein, C., Sprenger, A., et al. (2010). Eye movement disorders are different in Parkin-linked and idiopathic early-onset PD. Neurology. https://doi.org/10.1212/WNL.0b013e3181e7ca6d

Mirsky, J. B., Heuer, H. W., Jafari, A., et al. (2011). Anti-saccade performance predicts executive function and brain structure in normal elders. Cognitive and Behavioral Neurology, 24, 50-58. https:// doi.org/10.1097/WNN.0b013e318223f6c6

Mosimann, U. P., Müri, R. M., Burn, D. J., et al. (2005). Saccadic eye movement changes in Parkinson's disease dementia and dementia with Lewy bodies. Brain, 128, 1267-1276. https://doi. org/10.1093/brain/awh484

Nagai, K., Kaneko, Y., Suzuki, M., et al. (2019). Multimodal visual exploration disturbances in Parkinson's disease detected with an infrared eye-movement assessment system. Neuroscience Research. https://doi.org/10.1016/j.neures.2019.11.003

Nemanich, S. T., \& Earhart, G. M. (2016). Freezing of gait is associated with increased saccade latency and variability in Parkinson's disease. Clinical Neurophysiology. https://doi.org/10.1016/j.clinph. 2016.03.017

Obeso, I., Wilkinson, L., Casabona, E., et al. (2011). Deficits in inhibitory control and conflict resolution on cognitive and motor tasks in Parkinson's disease. Experimental Brain Research. https://doi. org/10.1007/s00221-011-2736-6

Ouerfelli-Ethier, J., Elsaeid, B., Desgroseilliers, J., et al. (2018). Antisaccades predict cognitive functions in older adults and patients with Parkinson's disease. PLoS One. https://doi.org/10.1371/journal. pone. 0207589

R Core Team. (2014). R: A language and environment for statistical computing. R Found Stat Comput Vienna, Austria URL http// wwwR-project.org/

Ranchet, M., Orlosky, J., Morgan, J., et al. (2017). Pupillary response to cognitive workload during saccadic tasks in Parkinson's disease. Behavioural Brain Research, 327, 162-166. https://doi. org/10.1016/j.bbr.2017.03.043

Rivaud-Péchoux, S., Vidailhet, M., Brandel, J. P., \& Gaymard, B. (2007). Mixing pro- and antisaccades in patients with parkinsonian syndromes. Brain, 130, 256-264. https://doi.org/10.1093/ brain/awl315

Rodríguez-Labrada, R., Velázquez-Pérez, L., Aguilera-Rodríguez, R., et al. (2014). Executive deficit in spinocerebellar ataxia type 2 is related to expanded CAG repeats: Evidence from antisaccadic eye movements. Brain and Cognition. https://doi.org/10.1016/j. bandc.2014.07.007

Rohatgi, A. (2015). WebPlotDigitizer. In: https://automeris.io/ WebPlotDigitizer/

Rothstein, H. R., Sutton, A. J., Borenstein, M. (2006). Publication Bias in Meta-Analysis. In: Publication Bias in Meta-Analysis: Prevention, Assessment and Adjustments

Sawamoto, N., Piccini, P., Hotton, G., et al. (2008). Cognitive deficits and striato-frontal dopamine release in Parkinson's disease. Brain. https://doi.org/10.1093/brain/awn054
Stewart, L. A., Clarke, M., Rovers, M., et al. (2015). Preferred reporting items for a systematic review and meta-analysis of individual participant data: The PRISMA-IPD statement. JAMA The American Journal of Medicine.

Stewart LA, Clarke M, Rovers M, Riley RD, Simmonds M, Stewart G, Tierney JF; PRISMA-IPD Development Group. Preferred Reporting Items for Systematic Review and Meta-Analyses of individual participant data: the PRISMA-IPD Statement. JAMA. 2015 Apr 28;313(16):1657-65. http://doi.org/10.1001/jama.2015.3656 PMID: 25919529.

Terao, Y., Fukuda, H., Ugawa, Y., \& Hikosaka, O. (2013). New perspectives on the pathophysiology of Parkinson's disease as assessed by saccade performance: A clinical review. Clinical Neurophysiology, 124, 1491-1506.

van Koningsbruggen, M. G., Pender, T., Machado, L., \& Rafal, R. D. (2009). Impaired control of the oculomotor reflexes in Parkinson's disease. Neuropsychologia. https://doi.org/10.1016/j.neuropsychologia. 2009.06.018

van Stockum, S., MacAskill, M., Anderson, T., \& Dalrymple-Alford, J. (2008). Don't look now or look away: Two sources of saccadic disinhibition in Parkinson's disease? Neuropsychologia. https:// doi.org/10.1016/j.neuropsychologia.2008.07.002

Viechtbauer W (2010) Conducting meta-analyses in R with the metafor. Journal of Statistical Software.

Visser, F., Bour, L. J., Lee, Y. X., et al. (2019). Eye movement abnormalities in essential tremor versus tremor dominant Parkinson's disease. Clinical Neurophysiology. https://doi.org/10.1016/j.clinph. 2019.01.026

Waldthaler, J., Tsitsi, P., Svenningsson, P. (2019a). Vertical saccades and antisaccades: complementary markers for motor and cognitive impairment in Parkinson's disease. NPJ Parkinson's Disease, 5:11. https://doi.org/10.1038/s41531-019-0083-7

Waldthaler, J., Tsitsi, P., Svenningsson, P. (2019b). Vertical saccades and antisaccades: complementary markers for motor and cognitive impairment in Parkinson's disease. NPJ Parkinson's Disease. https://doi.org/10.1038/s41531-019-0083-7

Walton, C. C., O'Callaghan, C., Hall, J. M., et al. (2015). Antisaccade errors reveal cognitive control deficits in Parkinson's disease with freezing of gait. Journal of Neurology. https://doi.org/10.1007/ s00415-015-7910-5

Wang, C. A., McInnis, H., Brien, D. C., et al. (2016). Disruption of pupil size modulation correlates with voluntary motor preparation deficits in Parkinson's disease. Neuropsychologia. https://doi. org/10.1016/j.neuropsychologia.2015.11.019

Yugeta, A., Hutchison, W. D., Hamani, C., et al. (2013). Modulation of beta oscillations in the subthalamic nucleus with prosaccades and antisaccades in Parkinson's disease. The Journal of Neuroscience. https://doi.org/10.1523/JNEUROSCI.2564-12.2013

Publisher's Note Springer Nature remains neutral with regard to jurisdictional claims in published maps and institutional affiliations. 